\title{
Influence of the selective layer morphology on the permeation properties for Pd-PSS composite membranes prepared by electroless pore-plating: experimental and modeling study
}

\author{
José Antonio Calles ${ }^{\mathrm{a}, *}$, Raúl Sanz ${ }^{\mathrm{a}}$, David Alique ${ }^{\mathrm{a}}$, Laura Furones ${ }^{\mathrm{a}}$, Pablo \\ Marín $^{\mathrm{b}}$, Salvador Ordoñez ${ }^{\mathrm{b}}$ \\ ${ }^{a}$ Department of Chemical and Energy Technology, Chemical and Environmental Technology, \\ Mechanical Technology and Analitycal Chemistry, Rey Juan Carlos University, C/ Tulipán \\ s/n, 28933 Móstoles, Madrid, Spain \\ ${ }^{b}$ Department of Chemical and Environmental Engineering, University of Oviedo, Faculty of \\ Chemistry, Julián Clavería 8, Oviedo 33006, Asturias, Spain
}

\begin{abstract}
The relationship between permeation behaviour and palladium layer morphology of a composite membrane prepared over a porous stainless steel support by Electroless Pore-Plating is presented in this work. Fully dense membranes were achieved with permeances in the range $7-18 \cdot 10^{-5} \mathrm{~mol} / \mathrm{m}^{2} \mathrm{sPa} a^{0.5}$, although the membrane morphology is clearly influenced by the synthesis conditions, particularly by the concentration of the Pd reducing agent (hydrazine). In this manner, a higher hydrazine concentration provokes the formation of a thicker external Pd film and, consequently, both external porosity and roughness decrease. On the other side, low hydrazine concentration facilitates the penetration of $\mathrm{Pd}$ inside the pores of the support. This fact, in turns, introduces an additional permeation resistance, which diminishes the hydrogen permeation flux and also introduces a threshold in the trans-membrane pressure value needed to allow hydrogen flux across the membrane. A new mathematical model, based on the Sieverts' law, is proposed to predict this particular behaviour, obtaining a good accuracy between both predicted and experimental data, including the gap in
\end{abstract}

\footnotetext{
${ }^{*}$ Corresponding author. Tel.: +34 914887378; fax: +34 914887068

Email address: joseantonio.calles@urjc.es (José Antonio Calles)
} 
the trans-membrane pressure. In this manner, the presented model can be used in multiple cases to design and optimize membranes modules prepared by Electroless Pore-Plating.

Keywords: Pd membrane, Pd layer morphology, permeation model, Electroless pore-plating, Hydrogen, Hydrazine

\section{Introduction}

The massive use of fossil fuels for energy generation provokes the emission of large amounts of anthropogenic carbon dioxide that contributes to the global warming, the urban smog, the acid rain and some health problems in humans [1].

5 The continuous grow in population, joined with the economic development, foments an increasing energy demand than makes this situation unsustainable for the future [2]. In this sense, great efforts are being made to mitigate this problem directed towards the substitution of fossil fuels as primary energy resource (i.e. renewable resources, hydrogen economy or nuclear fusion) and developing effective carbon capture processes [3]. In both cases, separation processes are critical for real industrial applications in favourable economic terms. Particularly, the development of a membrane technology for hydrogen separation has been of great interest in the last years. This technology is call to be a major contributor to the establishment of a hydrogen economy [4.

Accordingly to the United States Department of Energy, dense metallic membrane materials have to meet the following technical targets for competitive commercialization: i) $\mathrm{H}_{2}$ selectivity close to $100 \%$, ii) high permeability $\left(>680 \mathrm{scfh} / \mathrm{ft}^{2} / \mathrm{atm}^{0,5}\right.$ ) at $\mathrm{T}=400^{\circ} \mathrm{C}$ and $\Delta P=20 \mathrm{psi}$, iii) long-term stability at operating conditions (mechanical and thermal resistance) and iv) tolerance 20 to typical pollutants (i.e. carbon, $\mathrm{CO}$ or $\mathrm{H}_{2} \mathrm{~S}$ ) [5. In order to achieve all these requirements, different strategies are used to prepare the membranes. The incorporation of a palladium (or alloys) thin film over a porous support by electroless plating is one of the most suitable due to the uniformity and hardness of deposits, simplicity of the technique and good permeability [6]. However, the high 
investment cost is still one of the main drawbacks for the use of these membranes on a large scale [7]. This elevated cost is mainly due to the palladium and the support prices, as well as the amount of membranes rejected during the material synthesis. The main strategy to save costs is based on the preparation of ultrathin palladium layers, reducing the metal amount and maximizing 30 the permeation capacity of the membrane. Different alternatives have been proposed in the literature, such as the use of vacuum to fill the pores of the support with palladium by Zhang et al. 8, the combination of electroless plating with osmosis to facilitate the Pd incorporation around the pore area by Souleimanova et at. 9] or the preparation of pore-filled membranes in which the palladium 35 is incorporated as a internal layer on the support cross-section by Yogo et al. [10. However, the presence of defects such as wrinkles, cracks and pinholes is frequent during the synthesis of these really thin films. Thus, the repair of these defects can be also considered a good strategy to reduce the overall cost of the membrane preparation. In this way, Li et al. proposed a combination of electro-

40 less plating and osmosis, ensuring a complete disappearance of Pd layer defects without any reduction of permeability or increase in the metal thickness [11. Zeng et al. used a defect sealing via point plating by feeding the palladium salt and the reducing agent from opposite sides of the membrane [12. Differently, Lu et al. suggest the use of the intermetallic diffusion bonding to the reparation 45 process [13].

Recently, our group have reported a new alternative, denoted as electroless pore-plating (ELP-PP) to prepare completely dense membranes directly over porous stainless steel supports in a unique step, minimizing the generation of defects. It consists on forcing the reaction between $\mathrm{Pd}$ source and reducing agent to take place inside the pores by feeding both reactants from opposite sides of the support [14. Even though this methodology has demonstrated the possibility to obtain completely defect-free composite membranes, the particular conditions employed during the synthesis procedure is still under study.

On the other hand, not only the membrane preparation has been attracted growing attention but also the hydrogen permeation modelling through these 
$\mathrm{Pd}$-based membranes has been also a topic of great interest in the last years. Thus, mathematical models can be a great tool in the design and optimization of membrane modules, particularly when laboratory data must be translated into a commercial unit. Moreover, the use of the membrane as part of a membrane 60 reactor, e.g. for the water gas shift or methane reforming reactions [15, 16, require of adequate permeation models to make a successful coupling between the membrane and the reactor.

Hydrogen permeation through palladium metal is usually modelled using Sieverts' law, which is based on a solution-diffusion mechanism, with the palladium solid diffusion step being the controlling one. According to Sieverts' law, hydrogen permeation flux is proportional to the square root partial pressure gradient $p_{H_{2}}^{1 / 2}$. However, when using composite membranes formed by different material layers, other mass transfer resistances (i.3. in gas film, in the membrane support and interphase, etc.) may be of importance and the resulting

70 hydrogen permeation flux is reduced. Most of these mass transfer steps predicts a hydrogen permeation flux proportional to the partial pressure gradient $p_{H_{2}}$.

In the literature, there have been two approaches to model this situation with different type of gradients: formulate a transport equation for each individual step [17-23] or use only one empirical transport equation with unknown 75 exponent (n) for the partial pressure gradient [4, 24 26]. The later approach corresponds to the so-called Richardsons' law. The value of the exponent indicates the contribution of the different steps to the global process: $n$ close to $1 / 2$ implies that the mass transfer through the bulk palladium is the controlling step, while $\mathrm{n}$ close to 1 can be related to a influence of the mass transfer in the gas phase or support steps [4, 22, 25]. The formulation of a transport equation for each individual step is recommended, particularly when different transport steps are of importance, because this approach is more accurate when the model is used in the scale-up of the membrane.

In the present work the influence of reducing agent concentration to prepare composite Pd-Porous Stainless Steel (Pd-PSS) membranes by ELP-PP has been studied. Results have shown that this variable affects to the mor- 
phology of Pd layer and to the membrane permeability. The permeation results have been modelled by a rigorous approach, based on the explicit formulation of the individual transport steps. Finally, a modification of Sieverts' law has been proposed and validated to model the specific characteristics of the membranes used in the present work.

\section{Methodology}

\subsection{Membrane preparation}

All membranes presented in the present manuscript have been prepared following the general procedure described meticulously elsewhere [14]. Tubular porous stainless steel supports with $0.1 \mu \mathrm{m}$ grade, provided by Mott Metallurgical Corp., were used. Pieces of $30 \mathrm{~mm}$ in length were prepared by cutting the original ones. The membrane preparation procedure basically consists of three successive steps: i) initial cleaning, ii) activation and iii) palladium incorporation by ELP-PP. In the last step, the palladium source $(\mathrm{Pd}-$ ammonium complex) and the reducing agent (hydrazine) are fed by opposite sides of support in order to force the chemical reaction into the support pores. Three membranes have been prepared by using different reducing agent concentration: $0.05,0.20$ and $0.20 \mathrm{M}$. The $\mathrm{Pd}$ incorporation was repeated several times for each sample until obtaining a complete dense membrane. Between each cycle, the membrane is rinsed with deionized water and dried overnight at $110^{\circ} \mathrm{C}$. The complete density was evidenced by getting a negligible helium permeate flux at room temperature and pressure difference of 3 bar.

\subsection{Membrane characterization}

The characterization of the prepared membranes involves the structural analysis, examining aspects such as surface morphology, coverage uniformity, presence of defects, layer thickness or metal penetration in the pore area, as well as the permeation behaviour. 
The morphology of the membranes was analysed by Scanning Electron Mi-

\subsection{Membrane model}

In cylindrical membrane modules, hydrogen permeation takes place through the module wall and, as a consequence, the concentration of hydrogen in the retentate decreases along the axial coordinate. Hence, hydrogen partial pressure gradient at both sides of the membrane also changes along the axial coordinate. been formulated [17, 27]:

$$
\frac{d F_{H_{2} r}}{d A_{m}}=-J_{H_{2}}
$$




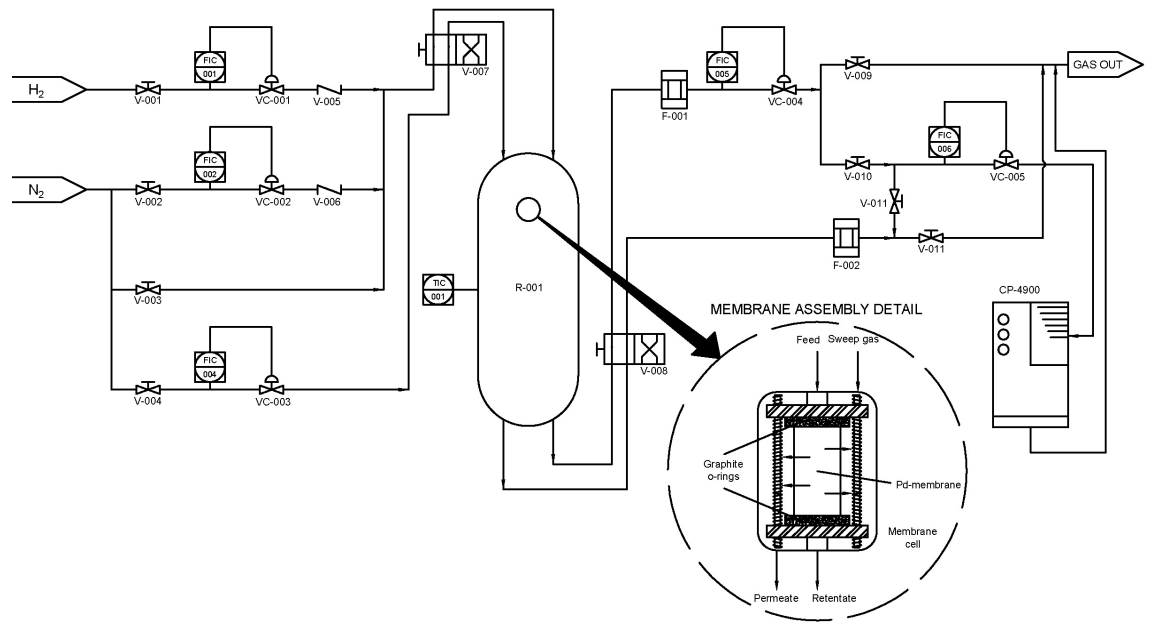

Figure 1: Experimental setup for permeation experiments

where $F_{H_{2} r}$ is the mole flow rate of hydrogen in the retentate, $A_{m}$ is membrane external area and $J_{H_{2}}$ is the local permeation flux.

This ordinary differential equation is solved using the following boundary condition: $\left.F_{H_{2} r}\right|_{A_{m}=0}=F_{H_{2} r, i n}$. The resolution has been done with the help of a MATLAB code based on function ode15s.

The average hydrogen flux for the entire membrane module can be calculated using the following mass balance to the whole membrane. Hydrogen flow rate at the outlet of the retentate side $F_{H_{2} \text { r,out }}$ is obtained after solving the previous differential equation.

$$
J_{H_{2} a v}=\frac{\left(F_{H_{2} r, \text { in }}-F_{H_{2} r, o u t}\right)}{A_{m}}
$$

The local hydrogen flux $J_{H_{2}}$ is calculated using the permeation model, explained in the following paragraphs, which is evaluated at the corresponding local hydrogen concentration.

The permeation model used in the present work accounts for the different mass transfer resistances of a cylindrical membrane to calculate the hydrogen 
flux. From the retentate side to the permeate side of the membrane the following resistances can be of importance in a palladium-based membrane: gas film, porous support and palladium layer. A mechanistic mass transfer model has been formulated for each resistance and then, the overall mass transfer rate is calculated by solving the resistances in series.

The gas film resistance appears when the permeability of the membrane is not tested with pure hydrogen. It should be noted that for the case of membranes completely selective to hydrogen, as in the present case, permeate is pure hydrogen, and hence the gas film is not formed at this side. For the retentate side of the membrane, the following equation is derived from the film theory [17.

$$
J_{H_{2}}=\frac{k_{p}}{\phi}\left(p_{H_{2} r}-p_{H_{2} s}\right)
$$

where $\phi=<1-p_{H_{2}}>_{\ln } / P_{r}$ is the correction factor for unidirectional mass transfer at high concentration (this factor arises when using a linear concentration gradient instead of a logarithmic one), $P_{r}$ is the absolute pressure in the retentate, $p_{H_{2} r}$ and $p_{H_{2} s}$ are the hydrogen partial pressure in the retentate and in the interface between the gas and internal surface of the support, respectively, and $k_{p}$ is the gas phase mass transfer coefficient based on partial pressures. This mass transfer coefficient is predicted from Sherwood number for transfer to the inside wall of a tube, $k_{p}=D_{i m} S h /\left(R T D_{t}\right)$, with $S h=3.66$ [28] and $D_{t}$ is the membrane internal diameter. The hydrogen diffusion coefficient in the gas mixture $\left(D_{i m}\right)$ has been calculated using correlations from the literature that takes into account variations in temperature, pressure and composition [28.

The porous support can also contribute with a resistance to mass transfer. The hydrogen flux is proportional to the hydrogen partial pressure gradient:

$$
J_{H_{2}}=\frac{k_{h}}{L_{s} R T}\left(p_{H_{2} s}-p_{H_{2} a}\right)
$$

where $k_{h}$ is the hydraulic permeability of the support $\left(\mathrm{m}^{2} / \mathrm{s}\right), p_{\mathrm{H}_{2} a}$ the hydrogen partial pressure in the interface between the external surface of the support 
and the internal surface of the $\operatorname{Pd}$ layer and $L_{S}$ is the support thickness. The hydraulic permeability can be calculated using the dusty-gas-model, which accounts for vand pressure difference of $\mathrm{DP}=3$ iscous flow (Hagen-Pouiselle) and Knudsen diffusion in porous media [19, 20]:

$$
k_{h}=\frac{\epsilon_{p} d_{\text {pore }}^{2} P_{r}}{32 \mu_{G} \tau}+D_{e K}
$$

where $d_{\text {pore }}$ is the average pore diameter, $\epsilon_{p}$ is the porosity and $\tau$ is the tortuosity of the support, $\mu_{G}$ is the gas viscosity, and $D_{e K}=\left(2 \epsilon_{p} d_{\text {pore }} / 3 \tau\right) \sqrt{2 R T / \pi M_{H_{2}}}$ is the effective Knudsen diffusion coefficient of the support, with $M_{\mathrm{H}_{2}}$ being molar weight of hydrogen.

The palladium layer is the active element of the membrane, being responsible of the separation achieved in the membrane. The mechanism of hydrogen mass transfer in the palladium layer can be simplified into two stages: hydrogen molecule dissociative adsorption and solution in the metal, and hydrogen atom diffusion 4. The latter, usually the controlling step, is modelled by Ficks' law. Hydrogen molecule dissociation and solution is modelled by the equilibrium expression. By combination, the so-called Sieverts' law is obtained [29]:

$$
J_{H_{2}}=\frac{Q}{L_{P d}}\left(p_{H_{2} a}^{1 / 2}-p_{H_{2} p}^{1 / 2}\right)
$$

where $Q$ is the metal permeability, $k_{P d}=Q / L_{P d}$ is the metal permeance of the membrane, $p_{H_{2} p}$ is the hydrogen partial pressure in the permeate and $L_{P d}$ is the metal layer thickness. $Q$, and hence $k_{P d}$, have an Arrhenius dependence with temperature, $k_{P d}=A e^{-E_{a} / R T}$ with activation energy, $E_{a}$.

The membranes used in the present work exhibit important palladium intrusion inside the pores of the support. Hydrogen molecules from the retentate side diffuse in the porous support and are adsorbed in the palladium of the inside of the pores. Then, hydrogen atoms diffuse in the palladium layer and are desorbed in the permeate side of the membrane. The permeate side of the membrane has no support, it is open to the gas phase. Hence, the gas-palladium interphase surface in the retentate side of the palladium layer is lower than in the 
permeate side, due to the presence of the porous support. This fact reduces the effective hydrogen partial pressure gradient and hence, the hydrogen flux of the membrane. To account for this effect the Sieverts' law has been modified with the introduction of a novel parameter, $\eta$, which is the ratio of the gas-palladium interphase surface in the retentate and permeate sides of the membrane:

$$
J_{H_{2}}=\frac{Q}{L_{P d}}\left(\eta p_{H_{2} a}^{1 / 2}-p_{H_{2} p}^{1 / 2}\right)
$$

In the appendix, a detailed deduction of the previous equation derived from the mechanism of hydrogen permeation in the palladium metal has been included. This modification of Sieverts' law constitutes a novelty in the modelling approach of palladium-based membranes for hydrogen separation.

The permeation model, formed by equations (3), (4) and (7), has been solved numerically for known $p_{H_{2} r}$ and $p_{H_{2} p}$ to determine the $J_{H_{2}}, p_{H_{2} a}$ and $p_{H_{2} s}$. The resulting local hydrogen permeation flux $\left(J_{H_{2}}\right)$ is substituted in equation (1) to calculate the retentate flow rate and concentration axial gradients.

The average hydrogen flux $\left(J_{H_{2} a v}\right)$ obtained in the permeation experiments has been fitted to the membrane model with two main objectives: determine the controlling mass transfer steps and the unknown membrane properties $\left(k_{h}\right.$, $Q$ and $\eta$ ). The fitting has been carried out using a MATLAB code based on the 225 least-square method (function lsqcurvefit).

\section{Results and discussion}

\subsection{Membrane morphology}

As it has been previously indicated, commercial porous stainless steel tubes with a grade $0.1 \mu \mathrm{m}$ were used as support for the membrane preparation. Figure

2302 shows the surface morphology of the support (PSS, Figure 2a), obtained from scanning electron microscopy, as well as the surface of the membranes prepared with an hydrazine concentration of $0.05 \mathrm{M}$ (PSS-Pd-01, Figure 2b), 0.20 M (PSS-Pd-02, Figure 2c) and 1.00 M (PSS-Pd-03, Figure 2d). The average 

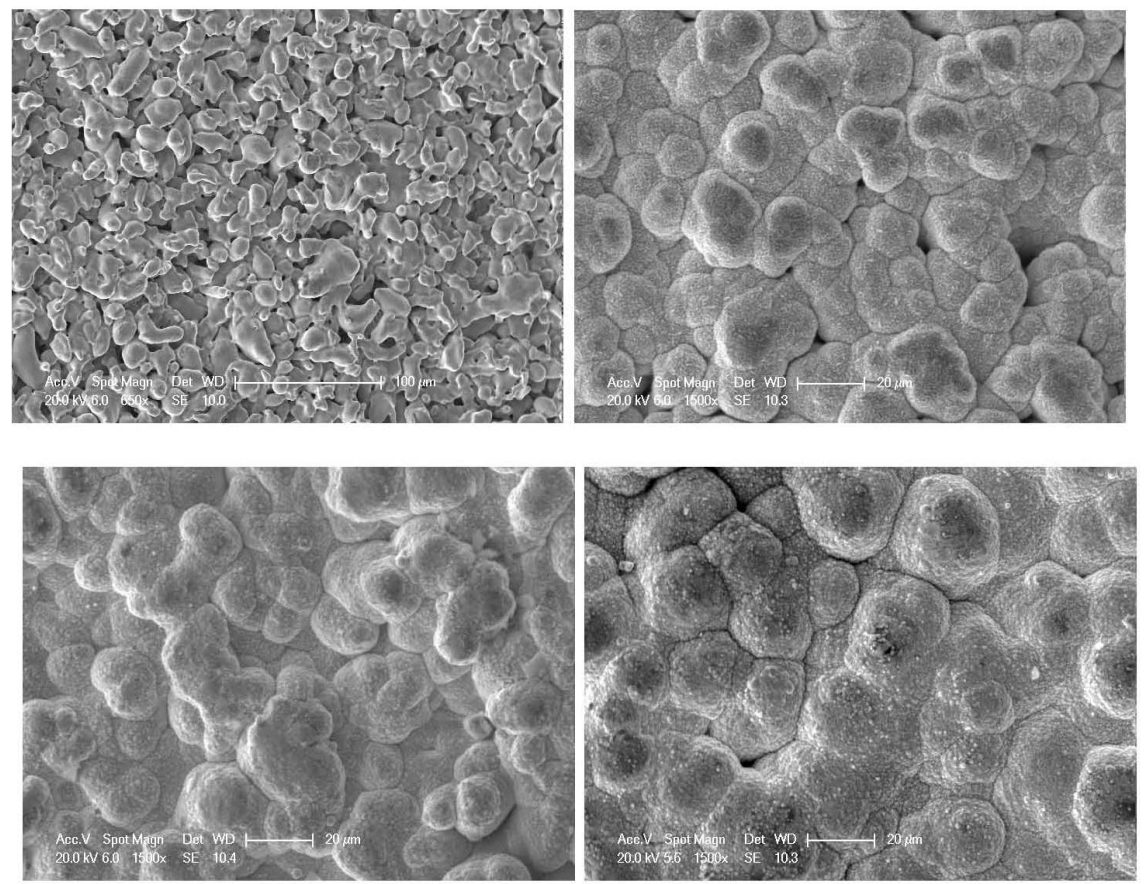

Figure 2: SEM images of the PSS support surface (a) and membranes obtained after Pd incorporation with diverse hydrazine concentration: $0.05 \mathrm{M}$ (b), $0.20 \mathrm{M}$ (c) and $1.00 \mathrm{M}$ (d).

porosity $(\varepsilon)$ and surface roughness $\left(\mathrm{R}_{a}\right)$ values for each sample are summarized in Table 1 .

The original PSS support presents $\varepsilon=18.6 \%$ and $\mathrm{R}_{a}=11.8 \mu \mathrm{m}$. External porosity drastically reduces after the palladium incorporation through ELP-PP, independently of the hydrazine concentration. Thus, an average porosity of $\varepsilon=$ $3.2 \%$ for PSS-Pd-01 and $\varepsilon=2.0 \%$ for PSS-Pd-03 were obtained, while a negligible porosity was detected for PSS-Pd-02. In this manner, a very homogeneous deposition is observed and only some remaining pores are detected.

It is important to emphasize that an external palladium layer was obtained in all cases, in spite of the chemical reaction between palladium source and hydrazine takes place preferentially in the internal pores of the support. This fact, apparently contrary to the electroless pore-plating method, has been explained in detail in our previous paper [14]. In summary, this behaviour can be 
Table 1: Pd layer properties of support and membranes.

\begin{tabular}{lcccc} 
Sample & $\mathrm{C}_{H}(\mathrm{M})$ & $\varepsilon(\%)$ & $\mathrm{R}_{a}(\mu \mathrm{m})$ & $\mathrm{t}(\mu \mathrm{m})$ \\
\hline PSS & - & 18.6 & 11.8 & - \\
PSS-Pd-01 & 0.05 & 3.2 & 10.8 & 16.2 \\
PSS-Pd-02 & 0.20 & 0.9 & 11.3 & 8.8 \\
PSS-Pd-03 & 1.00 & 2.0 & 6.8 & 22.0 \\
\hline
\end{tabular}

$\mathrm{C}_{H}$ : Hydrazine concentration; $\varepsilon$ : porosity;

$\mathrm{R}_{a}$ : Roughness; t: Pd averaged weight thickness.

explained by the wide pore size distribution of the raw support. The smallest pores can be easily closed with Pd particles, while hydrazine can pass through the larger pores, partially covered, generating an external layer. This external Pd layer makes the surface slightly smoother, decreasing the average roughness until values in the range of $\mathrm{R}_{a}=6-11 \mu \mathrm{m}$. This reduction can be also related to the Pd amount incorporated in the membrane. In this manner, the smoother surface $\left(\mathrm{R}_{a}=6.80 \mu \mathrm{m}\right)$ was obtained for the thick Pd layer $(\mathrm{t}=22.0 \mu \mathrm{m})$, when a higher hydrazine concentration is employed $\left(C_{N_{2} H_{4}}=1.00 \mathrm{M}\right.$, PSS-Pd-03).

255 In other cases, the estimated Pd thickness, obtained by gravimetric analysis, was reduced until $\mathrm{t}=16.2 \mu \mathrm{m}$ for PSS-Pd-01 $\left(C_{N_{2} H_{4}}=0.05 \mathrm{M}\right)$ and $\mathrm{t}=8.8$ $\mu \mathrm{m}$ for PSS-Pd-02 $\left(C_{N_{2} H_{4}}=0.20 \mathrm{M}\right)$. In both cases a roughness around $\mathrm{R}_{a} \approx$ $10 \mu \mathrm{m}$ is observed.

In this point, it is important to emphasize that remaining surface porosity obtained in some samples does not imply gas leaks due to the nature of the palladium deposition method. It is possible to obtain a completely dense membrane when most of the internal pores of the PSS support are filled with palladium, independently of the continuity in the external layer. In this sense, the performance of these membranes have to be evaluated through permeation measurements. 


\subsection{Membrane permeation}

In order to evaluate the permeation behaviour of the prepared membranes, diverse tests with pure gases and mixtures have been carried out in a temperature range of $350-450{ }^{\circ} \mathrm{C}$ and pressure difference interval of $0.25-2.50$ bar. First of all, it has to be pointed out that no nitrogen was detected in the permeate flux and thus all membranes were completely selective to hydrogen. Figure 3 and Figure 4 shows the permeation fluxes obtained at different conditions for membranes PSS-Pd-01 and PSS-Pd-02, respectively. The membrane prepared with a higher hydrazine concentration $\left(C_{N_{2} H_{4}}=1.00 \mathrm{M}\right.$, PSS-Pd-03) shows a ${ }_{275}$ Pd thickness very close to the obtained with pure hydrazine and is described in detail in previous paper [14. Since the permeation behavior of both membranes are very similar, the results obtained for these conditions have been omitted in this manuscript. 
a)

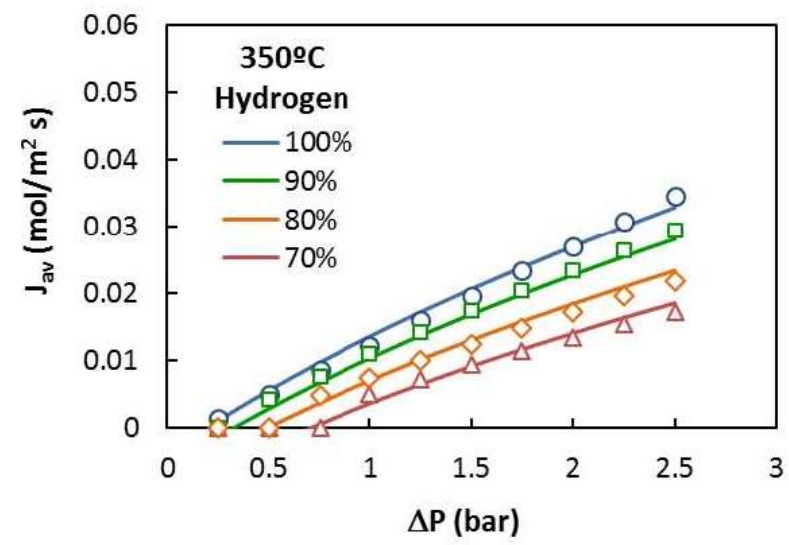

b)

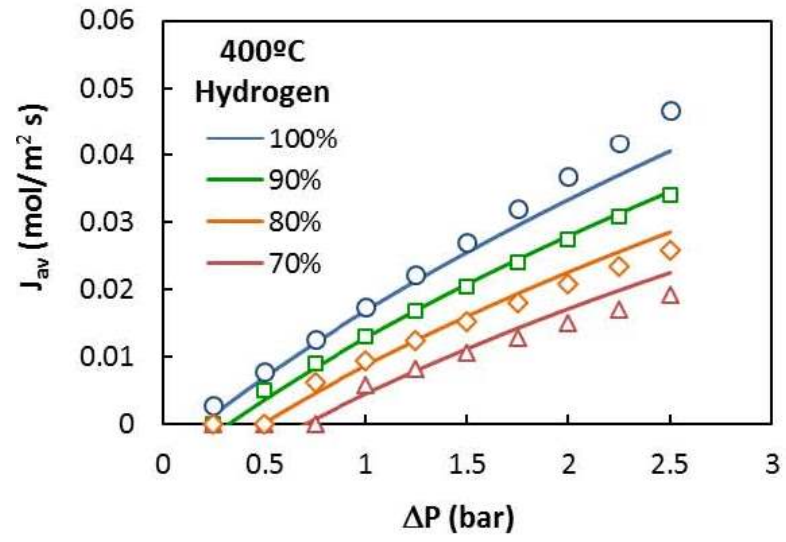

c)

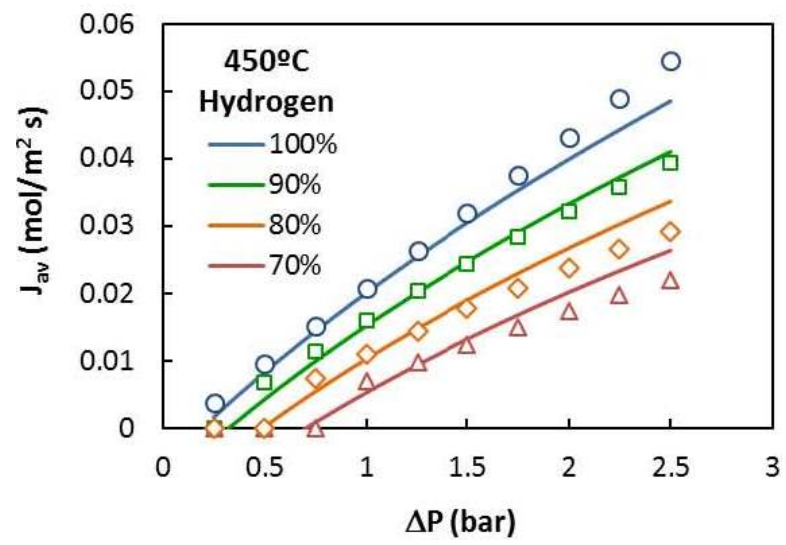

Figure 3: Membrane-averaged permeation flux of membrane MB02. Influence of total pressure gradient (0.5-2.5 bar), temperature, $350^{\circ} \mathrm{C}(\mathrm{a}), 400^{\circ} \mathrm{C}$ (b) and $450^{\circ} \mathrm{C}$ (c), and hydrogen concentration, $100(\bigcirc), 90(\square), 80(\diamond), 70\left(\triangle_{1}\right)_{4}$ Symbols: experiments. Lines: model fitting. 
a)

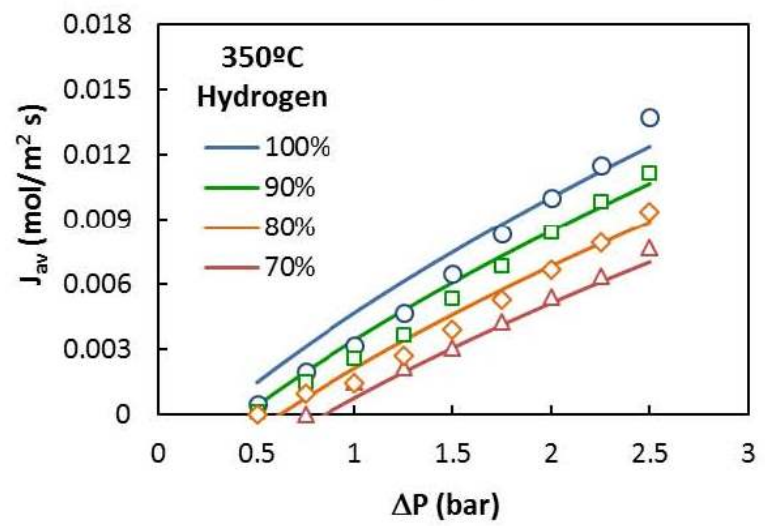

b)

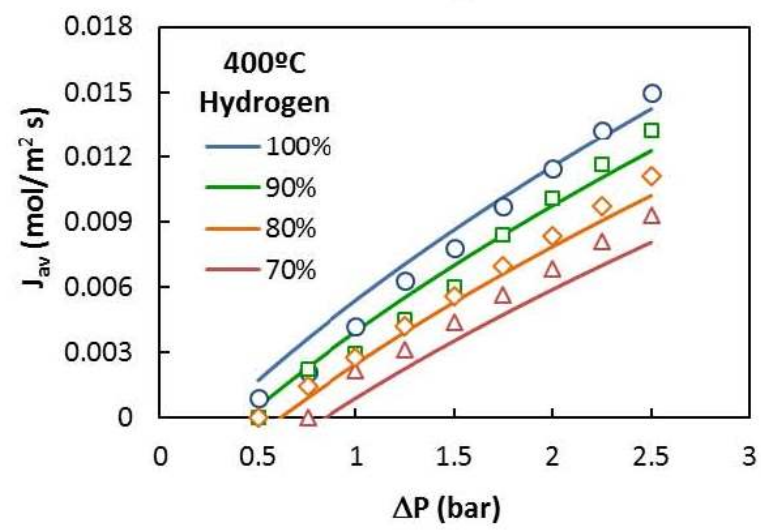

c)

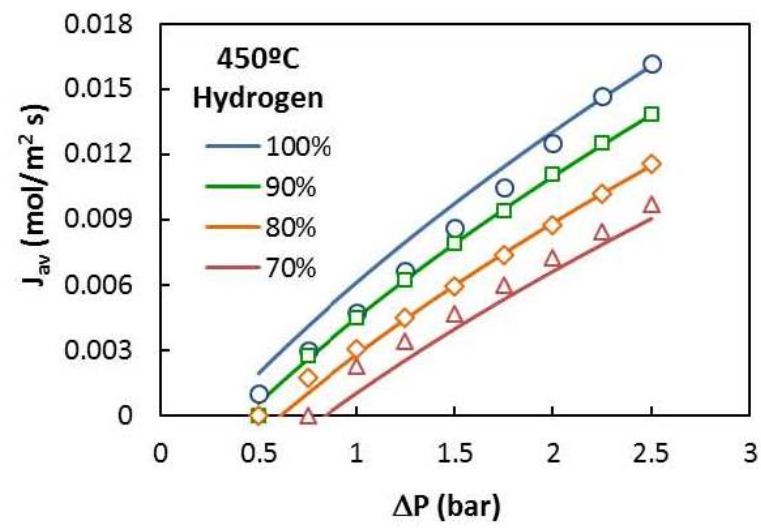

Figure 4: Membrane-averaged permeation flux of membrane MB05. Influence of total pressure gradient (0.5-2.5 bar), temperature, $350^{\circ} \mathrm{C}$ (a), $400^{\circ} \mathrm{C}$ (b) and $450^{\circ} \mathrm{C}$ (c), and hydrogen concentration, $100(\bigcirc), 90(\square), 80(\diamond), 70(\triangle)$. Symbols: experiments. Lines: model fitting. 
Focusing on the permeation fluxes obtained for the PSS-Pd-01 and PSSwith hydrogen/nitrogen mixtures, the gas film resistance was entirely predicted using a correlation from the literature, as explained in the methodology section. 
Table 2: Model parameters obtained by least-square fitting of the experimental data.

\begin{tabular}{lcc} 
& PSS-Pd-02 & PSS-Pd-01 \\
\hline Permeance $(673 \mathrm{~K}) 10^{5}$ & $17.9 \pm 0.8$ & $7.0 \pm 0.3$ \\
$\left(\mathrm{~mol} / \mathrm{m}^{2} \mathrm{~s} \mathrm{~Pa}^{1 / 2}\right)$ & & \\
Activation energy & $14.5 \pm 1.7$ & $9.7 \pm 1.8$ \\
$(\mathrm{~kJ} / \mathrm{mol})$ & $0.916 \pm 0.01$ & $0.88 \pm 0.01$ \\
Parameter $\eta$ & 0.974 & 0.968 \\
$R_{\text {adj }}^{2}$ & & \\
\hline
\end{tabular}

The results of the fitting are presented in Table 2 for both membranes.

310

layer thickne of membrane PSS-Pd 02 with recto to ther palladiun layer thickne of membrane PSS-Pd-02 with respect to PSS-Pd-01 (8.8 $\mu \mathrm{m}$ and $16 \mu \mathrm{m}$, respectively). To compare both membranes, regardless of their different palladium content, the metal permeance can be used, $Q=k_{P d} L_{P d}$. A value of ${ }_{325} 1.58 \cdot 10^{-9}$ and $1.12 \cdot 10^{-9} \mathrm{~mol} / \mathrm{m} \mathrm{s} \mathrm{Pa}^{1 / 2}$ are obtained, respectively, for membranes PSS-Pd-02 and PSS-Pd-01. The metal permeance of both membranes is not the same, but it is similar, and the discrepancy can be attributed to a different distribution of the palladium between the external layer and the pores.

Activation energy is also similar for both membranes, obtaining 14.5 and 9.7 
$\mathrm{kJ} / \mathrm{mol}$, respectively, for membrane PSS-Pd-02 and PSS-Pd-01, respectively. These values are in agreement with the typical activation energy for permeation in dense palladium, $15.5 \mathrm{~kJ} / \mathrm{mol} 30$.

Finally, the parameter $\eta$ is slightly different for both membranes. This value is a measurement of the ratio of the gas-palladium interphase surface at both sides of the palladium layer. Values of $\eta$ equal to 1 means that the adsorption positions at one side of the layer and the other are the same. In this case, the membrane PSS-Pd-01 has the lowest value, which is an indication that more palladium has intruded inside the pores of support of this membrane.

Figure 5 shows the SEM cross-section images of both membranes. As it can be clearly seen, the hydrazine concentration determine the relationship between the external $\mathrm{Pd}$ film and the penetration inside the pores. In this manner, an external Pd film of about 5 microns and a penetration of around 20-30 microns in depth was obtained for the membrane PSS-Pd-02, while the Pd incorporation inside the pores significantly increases as the hydrazine concentration decreases $\left(\mathrm{CN}_{2} \mathrm{H}_{4}=0.05 \mathrm{M}\right.$, PSS-Pd-01). Accordingly to this behaviour, a hydrazine concentration of $0.2 \mathrm{M}$ was selected as best conditions in order to prepare $\mathrm{Pd}$ composite membranes by Electroless Pore-Plating.
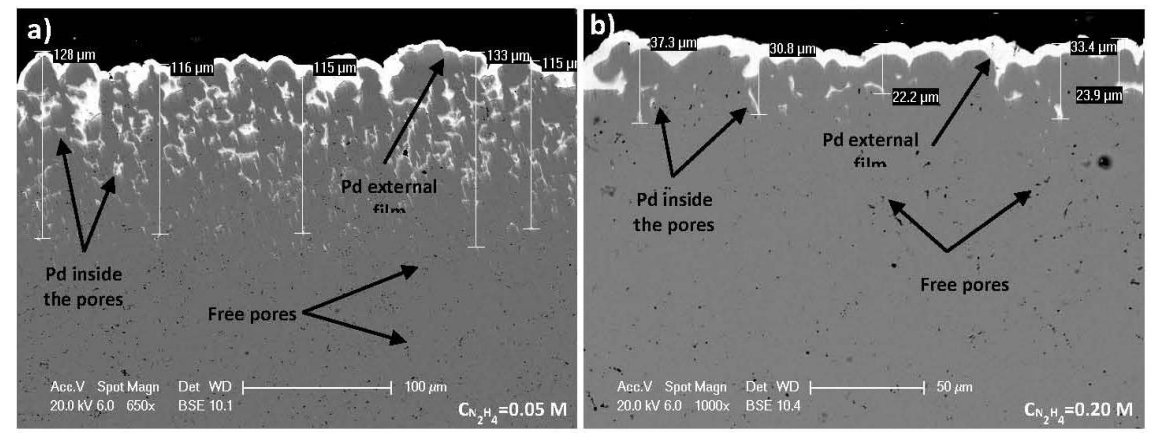

Figure 5: Cross sectional SEM images of membranes prepared with diverse hydrazine concentration: a) $\mathrm{CN}_{2} \mathrm{H}_{4}=0.05 \mathrm{M}$ (PSS-Pd-01) and b) $\mathrm{CN}_{2} \mathrm{H}_{4}=0.20 \mathrm{M}$ (PSS-Pd-02). 


\section{Conclusions}

Three different membranes were prepared through the electroless pore-plating

\section{Acknowledgment}

The authors would like to acknowledge the financial support of the XXXXXXXXX

\section{Appendix A. Deduction of the palladium permeation model}

The permeation model in the palladium has been deduced from the follow- 
from the gas adsorbs and dissociates on the palladium surface. Then, the hydrogen atoms diffuse through the solid palladium, which includes diffusion in the palladium inside the porous support and in the dense layer coated to the support. Finally, in the permeate side of the membrane hydrogen molecule is formed and desorbs into the gas phase. The diffusion step is considered the rate-limiting step of this mechanism, because of the thickness of the palladium layer of the membranes used in this work.

Hydrogen adsorption and desorption

Hydrogen adsorbs and dissociates on specific points of the palladium surface $385(\sigma)$, according to the following reaction:

$$
\mathrm{H}_{2}+2 \sigma \rightleftarrows 2 \mathrm{H}-\sigma
$$

This step is fast in comparison with the diffusion step, hence hydrogen concentrations can be considered in equilibrium. The adsorption equilibrium constant relates hydrogen gas partial pressure $\left(p_{H_{2}}\right)$ and hydrogen fractional adsorption $\left(\Theta_{H}\right)$ :

$$
K_{a d s}=\frac{\theta_{H}^{2}}{p_{H_{2}}\left(1-\theta_{H}\right)^{2}}
$$
adsorption is maintained low, so $\left(1-\Theta_{H}\right) \approx 1$, and hence [18]:

$$
\theta_{H}=\left(K_{a d s} p_{H_{2}}\right)^{1 / 2}
$$

\section{Hydrogen diffusion}

The diffusion of the hydrogen atom into the palladium metal is modelled by Ficks law, where mass transfer flux $\left(J_{H_{2}}\right)$ is proportional to the concentration 
difference of dissolved hydrogen $\left(X_{H}\right)$ at both sides of the palladium layer [19]:

$$
J_{H_{2}}=\frac{D_{H}}{L_{P d}}\left(X_{H}^{(1)}-X_{H}^{(2)}\right)
$$

The concentration of dissolved hydrogen is related to the hydrogen fractional adsorption, $X_{H}=\Omega \theta_{H}$, where $\Omega$ is the total molar concentration on the palladium surface. The $\Omega$ parameter is proportional to the gas-palladium interphase surface. In the membranes of the present work, the intrusion of palladium inside the pores of the support determines different interphase surfaces at both sides of the palladium layer, and hence $\Omega^{(1)}<\Omega^{(2)}$. By substituting into the flux expression:

Considering now equation 10 to relate fractional adsorption and partial pressure, and making the definition of the parameter $\eta=\Omega^{(1)} / \Omega^{(1)}<1$, the flux expression is simplified into the following expression:

$$
J_{H_{2}}=\frac{D_{H} \Omega^{(2)} K_{a d s}^{1 / 2}}{L_{P d}}\left(\eta\left(p_{H_{2}}^{(1)}\right)^{1 / 2}-\left(p_{H_{2}}^{(2)}\right)^{1 / 2}\right)
$$

Where $Q=D_{H} \Omega^{(2)} K_{a d s}^{1 / 2}$ is the metal permeability of the membrane.

\section{Notation}

Decidir si poner o quitar

Greek letters

410

Superscript

Subscript

\section{References}

[1] I. E. Agency, Key world energy statistics, publication/KeyWorld2014.pdf

q [2] S. Sorrell, Reducing energy demand: A review of issues, challenges and approaches, Renew. Sustain. Energy Rev. 47 (2015) 74-82. 


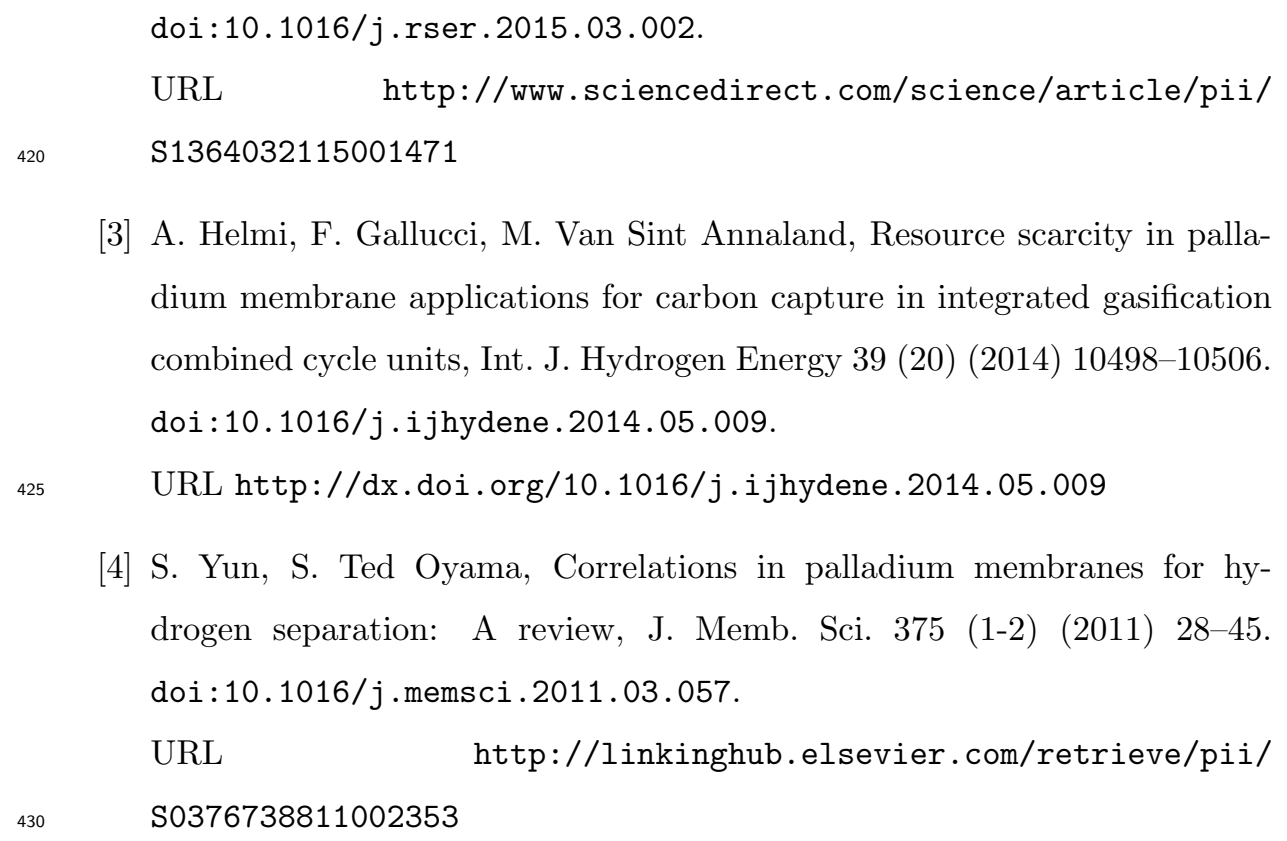

¿ [3] A. Helmi, F. Gallucci, M. Van Sint Annaland, Resource scarcity in palla-

․ dium membrane applications for carbon capture in integrated gasification combined cycle units, Int. J. Hydrogen Energy 39 (20) (2014) 10498-10506. doi:10.1016/j.ijhydene.2014.05.009.

${ }_{425}$ URL http://dx.doi.org/10.1016/j.ijhydene.2014.05.009

[1] S. Yun, S. Ted Oyama, Correlations in palladium membranes for hydrogen separation: A review, J. Memb. Sci. 375 (1-2) (2011) 28-45. doi:10.1016/j.memsci.2011.03.057. URL http://linkinghub.elsevier.com/retrieve/pii/ S0376738811002353

[5] D. O. of Energy Efficiency, R. Energy, Fuel cell technologies program multiyear research, development and demonstration plan, u.s. department of energy: Washington, d.c. (2007).

[6] Y. S. Cheng, K. L. Yeung, Effects of electroless plating chemistry on the synthesis of palladium membranes, J. Memb. Sci. 182 (1-2) (2001) 195-203. doi:10.1016/S0376-7388(00)00563-9.

¿ [7] X. Hu, J. Yu, J. Song, X. Wang, Y. Huang, Toward low-cost Pd/ceramic

[ composite membranes for hydrogen separation: A case study on reuse of the recycled porous Al2O3 substrates in membrane fabrication, Int. J. Hydrogen Energy 36 (24) (2011) 15794-15802. doi:10.1016/j.ijhydene. 2011.09.040.

URL http://dx.doi.org/10.1016/j.ijhydene.2011.09.040

[8] X. Zhang, G. Xiong, W. Yang, A modified electroless plating technique for thin dense palladium composite membranes with enhanced stability, J.

445 \ Memb. Sci. 314 (1-2) (2008) 226-237. doi:10.1016/j.memsci.2008.01. 051 . 
[9] R. S. Souleimanova, A. S. Mukasyan, A. Varma, Pd-composite membranes prepared by electroless plating and osmosis: Synthesis, characterization and properties, Sep. Purif. Technol. 25 (1-3) (2001) 79-86. doi:10.1016/ S1383-5866(01)00093-4

[10] K. Yogo, H. Takeyama, K. Nagata, Pore-fill-type palladium porous alumina composite membrane for hydrogen separation, Energy Procedia 37 (2013) 1104-1108. doi:10.1016/j.egypro.2013.05.207. URL http://dx.doi.org/10.1016/j.egypro.2013.05.207

[11] A. Li, W. Liang, R. Hughes, Repair of a Pd/ $\alpha$-Al2O3 composite membrane containing defects, Sep. Purif. Technol. 15 (2) (1999) 113-119. doi:10. 1016/S1383-5866(98)00087-2

[12] G. Zeng, A. Goldbach, H. Xu, Defect sealing in Pd membranes via point 口 plating, J. Memb. Sci. 328 (1-2) (2009) 6-10. doi:10.1016/j.memsci. 2008.11 .053

[13] N. Lu, D. Xie, F. Wang, Repair of palladium membrane modules by metallic diffusion bonding, Int. J. Hydrogen Energy 39 (32) (2014) 18659-18667. doi:10.1016/j.ijhydene.2014.02.027. URL http://linkinghub.elsevier.com/retrieve/pii/ S0360319914003875

[14] R. Sanz, J. A. Calles, D. Alique, L. Furones, New synthesis method of

a Pd membranes over tubular PSS supports via "pore-plating" for hydrogen separation processes, Int. J. Hydrogen Energy 37 (23) (2012) 18476-18485. doi:10.1016/j.ijhydene.2012.09.084. URL http://dx.doi.org/10.1016/j.ijhydene.2012.09.084

[15] R. Sanz, J. Calles, D. Alique, L. Furones, S. O. nez, P. Marín, Hydrogen production in a pore-plated pd-membrane reactor: Experimental analysis and model validation for the water gas shift reaction, International Journal

口 of Hydrogen Energy 40 (8) (2015) 3472 - 3484. doi:http://dx.doi.org/ $475 \quad 10.1016 / j . i j h y d e n e .2014 .11 .120$ 
[16] P. Marín, Y. Patiño, F. V. Díez, S. Ordóñez, Modelling of hydro-

口 gen perm-selective membrane reactors for catalytic methane steam reforming, Int. J. Hydrogen Energy 37 (23) (2012) 18433-18445. doi:10.1016/j.ijhydene.2012.08.147.

URL http://linkinghub.elsevier.com/retrieve/pii/ S0360319912019970

[17] R. Sanz, J. A. Calles, S. Ordóñez, P. Marín, D. Alique, L. Furones,

प Modelling and simulation of permeation behaviour on Pd/PSS composite membranes prepared by "pore-plating" method, J. Memb. Sci. 446 (2013) 410-421. doi:10.1016/j.memsci.2013.06.060.

URL http://linkinghub.elsevier.com/retrieve/pii/
S0376738813005619

[18] A. Caravella, G. Barbieri, E. Drioli, Modelling and simulation of hydrogen permeation through supported pd-alloy membranes with a multicomponent 490 a approach, Chemical Engineering Science 63 (8) (2008) 2149 - 2160. doi: http://dx.doi.org/10.1016/j.ces.2008.01.009

[19] A. Rossi, G. Lamonaca, A. Santucci, S. Tosti, Validation of a dynamic model of hydrogen permeation through pd-based membranes, International Journal of Greenhouse Gas Control 5 (3) (2011) 521 - 530, the 5thTrondheim Conference on $\{\mathrm{CO} 2\}$ Capture, Transport and Storage. doi:http://dx.doi.org/10.1016/j.ijggc.2010.11.009

[20] O. Schramm, A. Seidel-Morgenstern, Comparing porous and dense membranes for the application in membrane reactors, Chemical Engineering Science 54 (10) (1999) 1447 - 1453, 1st International symposium on multifunctional reactors. doi:http://dx.doi.org/10.1016/S0009-2509(99) 00062-7.

[21] T. L. Ward, T. Dao, Model of hydrogen permeation behavior in palladium 1 membranes, Journal of Membrane Science 153 (2) (1999) 211 - 231. doi: http://dx.doi.org/10.1016/S0376-7388(98)00256-7. 
[25] S.-K. Ryi, J.-S. Park, S.-H. Kim, S.-H. Cho, D.-W. Kim, K.-Y. Um, Characterization of pdcuni ternary alloy membrane prepared by mag-

[27] R. Sanz, J. Calles, D. Alique, L. Furones, S. Ordez, P. Marn, P. Corengia, 
E. Fernandez, Preparation, testing and modelling of a hydrogen selective pd/ysz/ss composite membrane, International Journal of Hydrogen Energy 36 (24) (2011) 15783 - 15793. doi:http://dx.doi.org/10.1016/j. ijhydene.2011.08.102.

[28] R. P. D.W. Green, Perry's Chemical Engineers' Handbook, 8th Edition, McGraw-Hill, 2008.

[29] R. E. Buxbaum, A. B. Kinney, Hydrogen Transport through Tubular Membranes of Palladium-Coated Tantalum and Niobium, Ind. Eng. Chem. Res. 35 (1996) 530-537. doi:10.1021/ie9501050

URL http://pubs .acs .org/doi/abs/10.1021/ie9501050

[30] F. Gallucci, E. Fernandez, P. Corengia, M. van Sint Annaland, Recent advances on membranes and membrane reactors for hydrogen production,

Chem. Eng. Sci. 92 (2013) 40-66. doi:10.1016/j.ces.2013.01.008

URL http://dx.doi.org/10.1016/j.ces.2013.01.008 